\title{
Interrupted time series design to evaluate ICD-9-CM to ICD-10-CM coding changes on trends in Colorado emergency department visits related to traumatic brain injury
}

\author{
Lauren Alexis De Crescenzo ${ }^{1}$ (B), Barbara Alison Gabella $2^{2^{*}}$ and Jewell Johnson² (B)
}

\begin{abstract}
Background: The transition in 2015 to the Tenth Revision of the International Classification of Disease, Clinical Modification (ICD-10-CM) in the US led the Centers for Disease Control and Prevention (CDC) to propose a surveillance definition of traumatic brain injury (TBI) utilizing ICD-10-CM codes. The CDC's proposed surveillance definition excludes "unspecified injury of the head," previously included in the ICD-9-CM TBI surveillance definition. The study purpose was to evaluate the impact of the TBI surveillance definition change on monthly rates of TBIrelated emergency department (ED) visits in Colorado from 2012 to 2017.

Results: The monthly rate of TBI-related ED visits was 55.6 visits per 100,000 persons in January 2012. This rate in the transition month to ICD-10-CM (October 2015) decreased by 41 visits per 100,000 persons ( $p$-value < 0.0001), compared to September 2015, and remained low through December 2017, due to the exclusion of "unspecified injury of head" (ICD-10-CM code S09.90) in the proposed TBI definition. The average increase in the rate was 0.33 visits per month $(p<0.01)$ prior to October 2015, and 0.04 visits after. When 509.90 was included in the model, the monthly TBI rate in Colorado remained smooth from ICD-9-CM to ICD-10-CM and the transition was no longer significant $(p=0.97)$.

Conclusion: The reduction in the monthly TBI-related ED visit rate resulted from the CDC TBI surveillance definition excluding unspecified head injury, not necessarily the coding transition itself. Public health practitioners should be aware that the definition change could lead to a drastic reduction in the magnitude and trend of TBI-related ED visits, which could affect decisions regarding the allocation of TBI resources. This study highlights a challenge in creating a standardized set of TBI ICD-10-CM codes for public health surveillance that provides comparable yet clinically relevant estimates that span the ICD transition.
\end{abstract}

Keywords: Traumatic brain injury, Hospital emergency department, Regression analysis, International classification of disease codes

\footnotetext{
* Correspondence: barbara.gabella@state.co.us

${ }^{2}$ Colorado Department of Public Health and Environment, 4300 Cherry Creek Drive South, A4, Denver, CO, USA

Full list of author information is available at the end of the article
}

(c) The Author(s). 2021 Open Access This article is licensed under a Creative Commons Attribution 4.0 International License, which permits use, sharing, adaptation, distribution and reproduction in any medium or format, as long as you give appropriate credit to the original author(s) and the source, provide a link to the Creative Commons licence, and indicate if changes were made. The images or other third party material in this article are included in the article's Creative Commons licence, unless indicated otherwise in a credit line to the material. If material is not included in the article's Creative Commons licence and your intended use is not permitted by statutory regulation or exceeds the permitted use, you will need to obtain permission directly from the copyright holder. To view a copy of this licence, visit http://creativecommons.org/licenses/by/4.0/ The Creative Commons Public Domain Dedication waiver (http://creativecommons.org/publicdomain/zero/1.0/) applies to the data made available in this article, unless otherwise stated in a credit line to the data. 


\section{Background}

Traumatic Brain Injury (TBI) is "caused by a bump, blow, jolt, or penetration to the head that disrupts normal function of the brain" (Faul et al. 2010). In Colorado, TBIs contributed to 13 percent of all injury-related emergency department (ED) visits from 2012-2014 based on health care billing data coded in the International Classification of Diseases, Ninth Revision, Clinical Modification (ICD-9-CM) (Colorado Department of Public Health 2015). On October 1, 2015 the US implemented the tenth revision, ICD-10-CM (National Center for Health Statistics 2015).

Epidemiologists at the CDC and other public health agencies in the US use ICD-coded health care administrative billing data for public health surveillance of TBI (CDC 2015; Marr and Coronado 2004). The CDC proposed definition for TBI surveillance using ICD-10-CM codes does not include S09.90 for "unspecified injury of the head" (Hedegaard et al. 2016). However, the ICD-9-CM TBI surveillance definition included 959.01 for "unspecified injury of head" (CDC 2015; CDC 2006; Faul et al. 2010; Marr and Coronado 2004; Taylor et al. 2017) even after the publication of the Barell matrix that excluded unspecified head injury as a TBI (Barell et al. 2002; The Israeli Center for Trauma and Emergency Medicine Research 2005). ICD-10-CM codes provide more detail regarding the clinical nature of an injury (National Center for Health Statistics 2015), and the transition to ICD-10-CM could provide CDC the opportunity to better align the TBI surveillance definition with the clinical diagnosis of TBI and the injury diagnosis framework for ICD-10CM (Hedegaard et al. 2020).

To date, no studies have assessed the effects of the transition on TBI-related ED visits and the inclusion/exclusion of unspecified head injury in the surveillance definition on trends spanning the coding transition. Studies assessed the positive predictive values (PPV) of the ICD-10-CM codes for TBI and unspecified head injury treated in the EDs or the PPV of TBI codes among hospitalizations but did not assess the impact of the proposed change in the surveillance definition on the magnitude and trend in TBI rates (Gabella et al. 2021; Peterson et al. 2021; Warwick et al. 2020). Studies have assessed changes in TBI ED rates during the ICD-9-CM era, but have not assessed trends for a period covering the transition to ICD-10-CM as well (Hsia et al. 2018; Taylor et al. 2017). One study of the transition to ICD10-CM using interrupted time series focused on TBIrelated hospitalizations among a subpopulation of adults aged 19-44 years in 2011-2017 where the primary reason (principal diagnosis) for the hospitalization was any traumatic injury (Sebastião et al. 2021).

The purpose of the study is to assess the impact of the transition to ICD-10-CM and the TBI definition change, specifically the exclusion of the code S09.90, on TBIrelated ED visit trends among all ages from 2012 to 2017 in Colorado. The study is intended to raise awareness about the transition to ICD-10-CM to assure accurate interpretation of TBI trends using new coding guidelines (Slavova et al. 2018; Sebastião et al. 2021).

\section{Methods}

The study team analyzed administrative billing data on ED visits for Colorado residents treated and released in Colorado non-federal, acute care hospitals from January 1, 2012 through December 31, 2017. At the time of the analysis, the data available were through 2017. This period provided more than 8 data points (rates) before and after the transition to ICD-10-CM, thereby providing enough power to detect change (Penfold and Zhang 2013). This period was long enough to account for seasonality in TBI-related ED visits.

The administrative billing records for ED visits contain standard information that hospitals must submit to private and government health insurance programs for reimbursement of treatment or to patients to pay, if they do not have health insurance (National Uniform Billing Committee 2021). Study staff searched all 30 discharge diagnoses fields on each billing record for any of the TBI codes. The ICD9-CM codes used to identify TBI were: $800.0-801.9$ (vault or basilar skull fracture), 803.0-804.9 (other skull fractures), 850.0-854.1 (intracranial injury, including concussion), 950.1-950.3 (injury to optic chiasm; optic pathways; visual cortex), 995.55 (shaken baby syndrome), and 959.01 (head injury, unspecified) (Marr and Coronado 2004). The ICD-10-CM codes proposed by CDC to identify TBI were: S02.0, S02.1- (fracture of skull), S02.8 (Fracture of other specified skull and fracture bones), S02.91 (unspecified fracture of skull), S04.02, S04.03-, S04.04- (injury to optic chiasm; optic tract and pathways; visual cortex), S06(intracranial injury), S07.1 (crushing injury of skull), and T74.4 (shaken infant syndrome) but not code S09.90 for "unspecified injury of head" (Hedegaard et al. 2016).

A concept unique to the ICD-10-CM is the type of encounter (for active treatment, planned procedures in the recovery phase, or treatment of a sequela) indicated by seventh character in the codes. For greater comparability with ICD-9-CM selection criteria, excluded were ED billing records with only a proposed TBI ICD-10-CM code with a seventh character of "S", indicating sequelae of TBI (Hedegaard et al. 2016). Not using ICD-9-CM codes for late effects and excluding records with ICD-10-CM codes indicating sequelae does not mean that the resulting TBIrelated ED visits reflect visits for incident cases of TBI.

The outcomes were the monthly rates of TBI-related ED visits among the study population. Monthly rates were computed as a function of the total number of ED visits with a TBI code in each month. Specifically, the numerator for a rate was the monthly number of TBI- 
related ED visits. The denominators used to compute the monthly rate of TBI per 100,000 persons were annual state population estimates from the Colorado Department of Local Affairs (2018). The billing data did not contain an identifier to track individuals with multiple visits in a month or with multiple TBIs in a month, so the rates reflect rates of visits, not patients.

Trends in crude monthly rate of TBI-related ED visits were assessed with two regression models. The first model used rates based on the commonly used ICD-9-CM definition (that includes unspecified head injury) and the proposed CDC TBI surveillance definition that excludes unspecified head injuries after Oct 1, 2015. The second model used the same monthly rates for the ICD-9-CM era and for the ICD-10-CM era, used re-calculated rates with counts of unspecified injury of head (ICD-10-CM code S09.90) added to the numerator of TBI-related ED visits.

The statistical model was a segmented regression using an interrupted time series design based on a detailed methodology in Slavova et al. (2018) The analysis was conducted with SAS 9.4@ 2018, using the SAS function PROC AUTOREG to estimate autoregressive parameters with a BACKSTEP option to select the correct order of parameters in the autoregressive error model. An alpha level of 0.05 was used to determine significance. The following regression model was used for analysis. Table 1 explains what each variable in the regression model means.

$$
\begin{aligned}
\mathrm{Y}_{\mathrm{t}}= & \beta_{0}+\beta_{1} * \text { time }_{\mathrm{t}}+\beta_{2} * \mathrm{ICD} 10 \mathrm{CM}_{\mathrm{t}} \\
& +\beta_{3} * \text { time_after_ICD10CM } \\
& +v_{\mathrm{t}}
\end{aligned}
$$

\section{Results}

At the beginning of the study period (January 2012), the monthly rate of TBI-related ED visits per 100,000 persons was $55.6(p<.0001)$ with an average increase of 0.33 TBI-related ED visits per month $(p<.0001)$. By the end of the ICD-9-CM coding era (September 2015), the monthly rate had increased to $70.3(p<.0001)$.

From the first estimation model where TBI included unspecified head injury before but not after the transition to ICD-10-CM, the monthly rate in the first month of the ICD-10-CM era (October 2015) was 29.3, a decrease of 41 visits per 100,000 $(p<.0001)$ from the prior month. After the ICD transition, the average monthly rate increase from October 2015 through December 2017 was 0.04 (Fig. 1), a decrease of 0.29 per 100,000 $(p=0.0004)$ from the ICD-9-CM era. This autoregressive model detected and accounted for positive serial correlation of the error terms every 12 months.

Using the second estimation model, with inclusion of ICD-10-CM code S09.90, the transition to ICD-10-CM in October 2015 was not significant $(p=0.94)$ and resulted in a smooth trend over time (Fig. 2). The average monthly rate from October 2015 through December 2017 increased by 0.12 , a decrease by 0.20 per 100,000 persons $(p=0.04)$ from the ICD-9-CM era.

\section{Discussion}

Our findings suggest that the exclusion of code S09.90 contributed to the immediate decrease of 41 visits per 100,000 persons in the monthly rate of TBI-related ED visits in October 2015. This decrease represented over half of the monthly rate in September 2015. The proportion of TBI-related ED visits with 959.01 from 2012 through 2015 was constant, and therefore, does not explain the higher average increase in the monthly rate during the ICD-9-CM era compared to the ICD-10-CM era ( 0.33 vs. 0.12 from the first model). Unspecified head injuries (code 959.01) represented 64\% of the TBIrelated ED visits in 2012, 62\% in 2013 and 2014, and

\begin{tabular}{|c|c|}
\hline Variable & Description \\
\hline$Y_{t}$ & The rate of TBI related ED visits per 100,000 population in a given month (t). \\
\hline time $_{\mathrm{t}}$ & Represents month values from 1 (January 2012) to 72 (December 2017). \\
\hline$\beta_{0}$ & The intercept or the outcome at the start of the ICD-9-CM period (baseline level at time 0, $t=0$, of December 2011) \\
\hline$\beta_{1}$ & $\begin{array}{l}\text { The coefficient for the independent variable of time, that starts at } 1 \text { for the first month and } 72 \text { for the last month } \\
\text { for the } 72 \text { total months in the six-year period from January } 2012 \text { to December } 2017\end{array}$ \\
\hline$\beta_{2}$ & The coefficient indicating the level of change in the rate of TBI-related ED visits immediately after the transition \\
\hline ICD10CM & $\begin{array}{l}\text { A dummy variable indicating the start of ICD-10-CM (the interruption in the time series) is } 0 \text { for each month prior to } \\
\text { October 2015, and } 1 \text { for each month beginning October } 2015 \text { and after. }\end{array}$ \\
\hline$\beta_{3}$ & $\begin{array}{l}\text { The coefficient indicates the change in the slope of the monthly TBI rate after the transition to ICD-10-CM, compared } \\
\text { to slope } \beta_{1}\end{array}$ \\
\hline time_after_ICD10CM & $\begin{array}{l}\text { The variable indicates in rank order or sequential order the months at and after the beginning of ICD-10-CM. This } \\
\text { variable is } 0 \text { prior to ICD-10-CM, } 1 \text { for October 2015, } 2 \text { for November 2015, } 3 \text { for December 2015, etC. }\end{array}$ \\
\hline$v_{t}$ & The error term represents the random variability not explained by the variables in model \\
\hline
\end{tabular}

Table 1 Variables in the Interrupted Time Series equation ${ }^{\text {a }}$

${ }^{a}$ Slavova et al. (2018) provides further explanation of the variables 


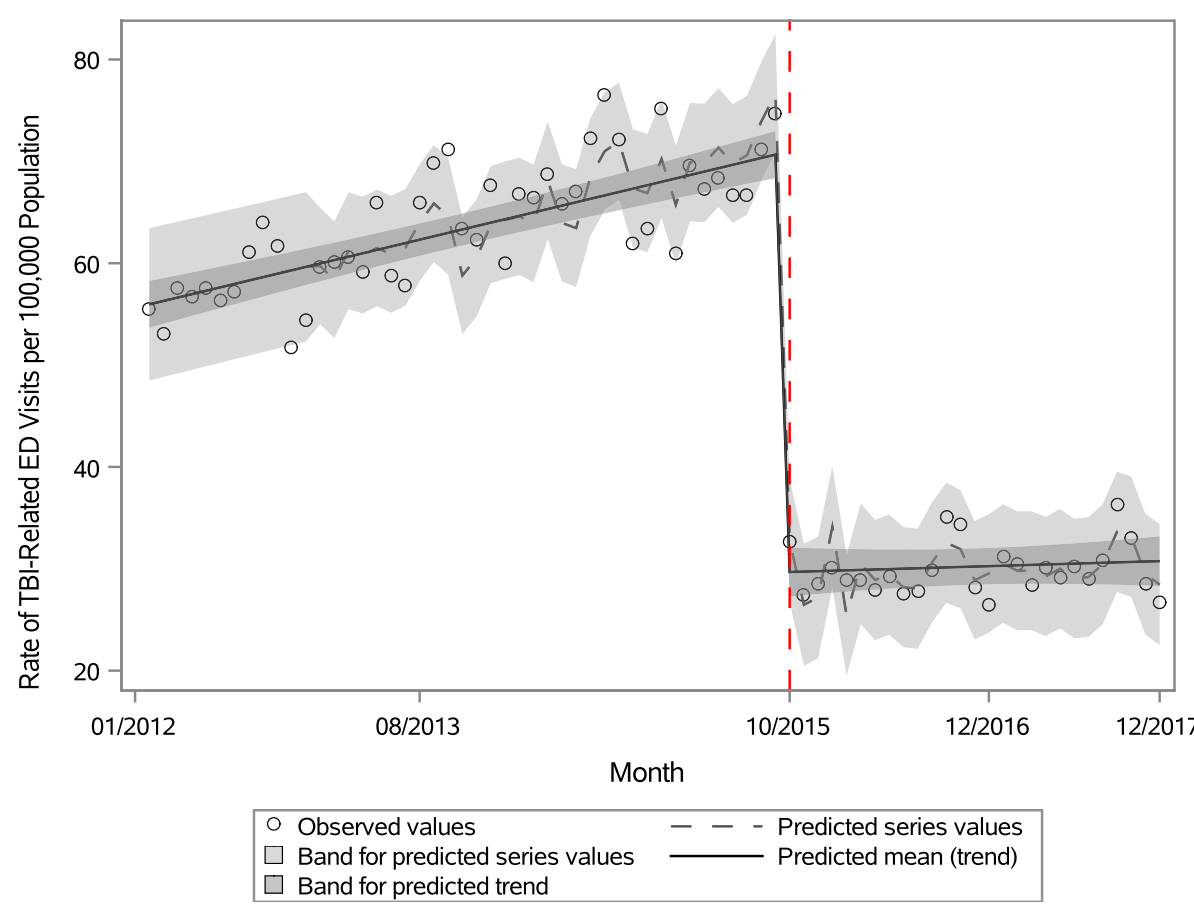

Fig. 1 Monthly rates of TBI-related emergency department visits per 100,000 Colorado residents, 2012-2017 ${ }^{\text {a }}$ Figure 1 Footnote: Red dotted line on October 1, 2015 indicates the start of ICD-10-CM in the United States. Traumatic brain injury (TBI) estimates after the transition to ICD-10-CM (marked by red dotted line) do not include unspecified injury of head

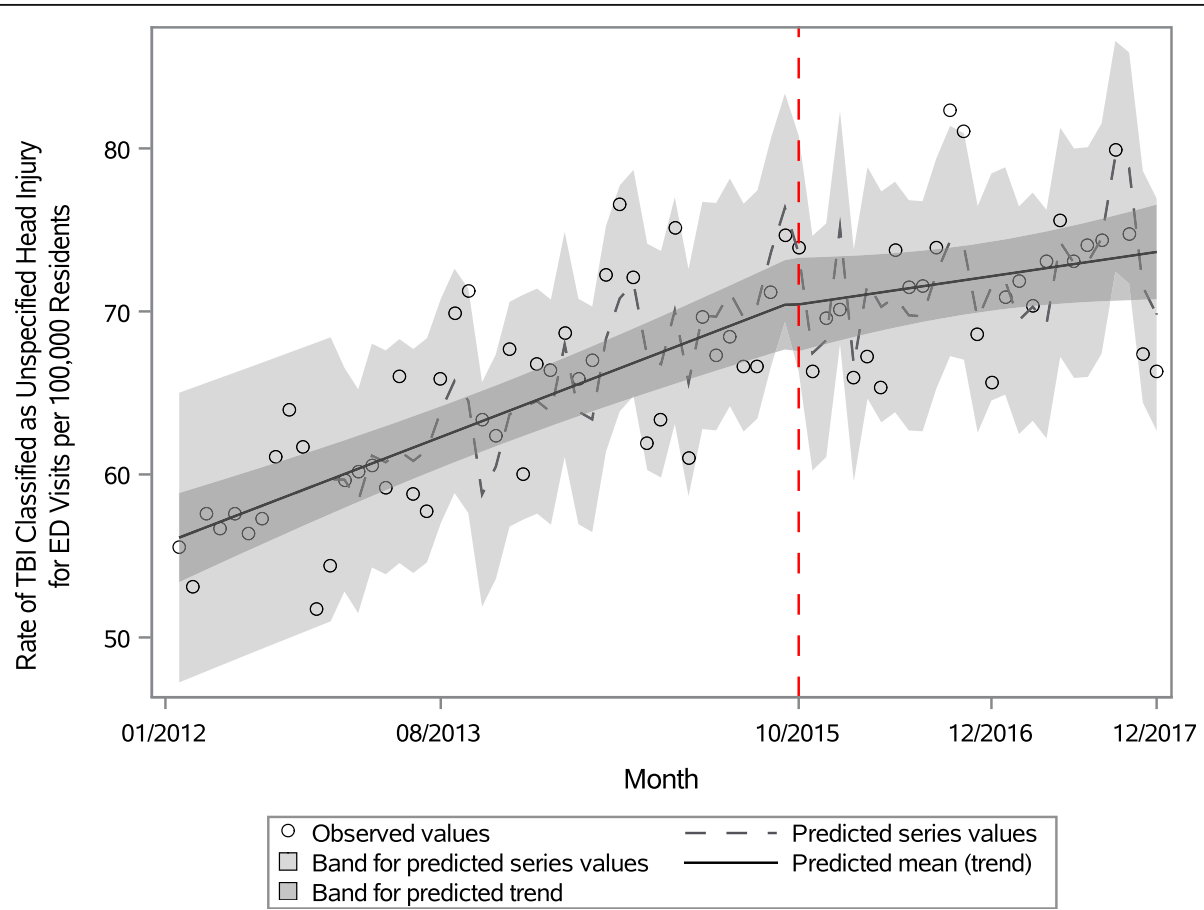

Fig. 2 Monthly rates of TBI-related Emergency Department Visits per 100,000 Colorado Residents (with S09.90), 2012-2017b. bigure 2 Footnote: Red dotted line on October 1, 2015 indicates the start of ICD-10-CM in the United States. Traumatic brain injury estimates after the transition to ICD-10-CM (marked by red dotted line) include unspecified injury of head (S09.90) 
$62 \%$ in the first 9 months of 2015. Structural changes in specific ICD-10-CM codes for TBI, compared to ICD-9CM codes, appear to have expanded the capture of TBI post transition, including potentially false-positive TBI (Sebastião et al. 2021). These structural code changes might have contributed to the remaining increase in average monthly rates post transition, even after including unspecified head injury (the second model).

Additionally, the upward trend in TBI-related ED visits during both ICD-CM eras could be attributed to many factors: willingness to seek medical care and visit an ED, increased health insurance coverage, older adults with a higher incidence of TBI among an aging population, and/or increased incidence of TBI (Hsia et al. 2018; Nikpay et al. 2017). Reporting bias due to shifting care from EDs to urgent care or outpatient settings during the ICD-10-CM period seems an unlikely alternative explanation of the study findings, unless such shifting occurred differently for patients treated and released from EDs with TBI diagnoses than for patients diagnosed with unspecified head injury. However, some of the increase could reflect increase in ED capacity over this time period. Overall, Colorado ED visits with any diagnosis increased 8.7\% from 2013 to 2017, and the number of acute care hospitals and general licensed hospitals with EDs in Colorado increased 7.4\% from 81 in 2012 to 87 in 2017.

This study also found seasonality. The seasonality or correlation every 12 months in monthly TBI-related ED visits could result from the seasonality in the mechanism of injury, which another state documented (Slavova et al. 2018). As an example, the snow conditions every January in Colorado could be similar and could affect driving conditions that increase motor-vehicle related TBIs. January is also ski season in Colorado. Summer months could bring increased recreational activities, such as hiking, biking, amateur sports, and vacation driving.

Study limitations include not assessing other factors that could have influenced monthly TBI-related ED visit rates such as legal changes and increased awareness of brain injury among the public (National Conference of State Legislators 2018; CDC 2015). The study results are not necessarily representative of other states or countries. This study did not assess whether training or other preparation for the ICD-10-CM transition influenced physician medical record documentation or the accuracy of billing diagnosis coding. The study did not cluster data by hospital or account for differences in coding or billing practices by hospital, potentially resulting in a type-1 error inflation. Finally, ICD-CM codes are designed for billing purposes and have imperfect sensitivity and specificity when used for surveillance purposes.

The monthly TBI rate between 2012 and 2015 may overestimate the true TBI rate. A validation study of the TBI ICD-9-CM definition in ICD-9-CM in the ED at a large urban hospital in 2003 found that only $20 \%$ of cases coded with 959.01 for unspecified head injury met the clinical definition of TBI (Table 3 in Bazarian et al. 2006). Additionally, the Barell Matrix, utilized by $\mathrm{CDC}$, does not include the ICD-9-CM code 959.01 in the TBI definition and considers these injuries "other head, face and neck" (Barell et al. 2002; The Israeli Center for Trauma and Emergency Medicine Research 2005).

A strength of this study is that it was a large statewide study with numerous acute care hospitals, and not limited to one hospital or one hospital system. The regression models accounted for seasonality, corrected the regression estimates for the positive autocorrelation of the error terms, and assessed any changes in magnitude and trend of the monthly rates of ED visits per 100,000 population due to including or excluding unspecified head injuries in the TBI surveillance definition.

\section{Conclusions}

This study shows the importance of understanding the diagnosis codes used to define monthly rates of TBIrelated ED visits. The drastic reduction in the trend of TBI estimates after October 1, 2015 using ICD-10-CM codes, could affect decisions regarding the allocation of TBI resources. Public health practitioners should be aware that this interruption is primarily due to the change in the TBI surveillance definition and not the coding transition itself or its limitations.

This study highlights a challenge in creating a standardized set of TBI ICD-10-CM codes for public health surveillance that provides comparable yet clinically relevant estimates over time. These study results based on 6 years of ED billing data from a single state can help inform the next steps for finalizing a public health surveillance definition of TBI until the next major change in the ICD-CM coding scheme, and this study should be repeated in other states and jurisdictions.

\footnotetext{
Acknowledgements

The authors would like to thank Svetla Slavova, PhD and co-authors for providing detailed methodology in the publication that made this study possible, and Alexis Peterson, PhD for providing subject area expertise in support of this project.
}

\section{Authors' contributions}

BAG conceptualized the study and analysis plan and replicated the results. $\mathrm{LAD}$ and $\mathrm{J} \mathrm{J}$ implemented the analysis. All authors (LAD, BAG, and JJ) contributed to the interpretation of findings and drafting and revising the manuscript. The author(s) read and approved the final manuscript.

\section{Funding}

This publication was supported in part by Grant Number 6NU17CE92484103 from the Centers for Disease Control and Prevention in the United States Health and Human Services Department (HHS). Its contents are solely the responsibility of the authors and do not necessarily represent the official views of the HHS or the Colorado Department of Public Health and Environment or the Colorado Hospital Association. 


\section{Availability of data and materials}

The datasets used and/or analyzed during the current study are available from the corresponding author on reasonable request.

\section{Ethics approval and consent to participate}

Not applicable.

\section{Consent for publication}

Not applicable.

\section{Competing interests}

The authors declare that they have no competing interests.

\section{Author details}

${ }^{1}$ Colorado School of Public Health, Denver, CO, USA. ${ }^{2}$ Colorado Department of Public Health and Environment, 4300 Cherry Creek Drive South, A4, Denver, CO, USA.

Received: 22 December 2020 Accepted: 16 February 2021 Published online: 19 April 2021

\section{References}

Barell V, Aharonson-Daniel L, Fingerhut LA, et al. An introduction to the Barell body region by nature of injury diagnosis matrix. Inj Prev. 2002;8:91-6 https://injuryprevention.bmj.com/content/injuryprev/8/2/91.full.pdf Accessed on 31 Jan 2021.

Bazarian J, Veazie P, Mookerjee S, et al. Accuracy of mild traumatic brain injury case ascertainment using ICD-9 codes. Acad Emerg Med. 2006;13(1):31-8. https://doi.org/10.1197/j.aem.2005.07.038 Epub 2005 Dec 19.

Centers for Disease Control and Prevention (CDC). Incidence rates of hospitalization related to traumatic brain injury--12 states, 2002. MMWR. 2006;55:201-4 https://www.cdc.gov/mmwr/preview/mmwrhtml/mm5508a2. htm Accessed on 31 Jan 2021.

Centers for Disease Control and Prevention (CDC). Report to Congress on Traumatic Brain Injury in the United States: Epidemiology and Rehabilitation. Atlanta: National Center for Injury Prevention and Control; 2015. https:// www.cdc.gov/traumaticbraininjury/pdf/tbi_report_to_congress_epi_and_ rehab-a.pdf Accessed 12 Jan 2021.

Colorado Department of Local Affairs. Population Data. 2018. https://demogra phy.dola.colorado.gov/population/ Accessed 1 Oct 2018.

Colorado Department of Public Health and Environment. Injury in Colorado, 2012-2014. Denver; 2015. https://drive.google.com/file/d/11 FllvoTC5L7jUmQ-_hSIbYSygfdh_mSR/view. Accessed 20 Dec 2020.

Faul M, Xu L, Wald MM, Coronado VG. Traumatic Brain Injury in the United States: Emergency Department Visits, Hospitalizations and Deaths 2002-2006. Atlanta: National Center for Injury Prevention and Control, Centers for Disease Control and Prevention; 2010.

Gabella B, Hathaway JE, Hume B, Johnson J, Costich JF, Slavova S, Liu AY. Multisite medical record review of emergency department visits for traumatic brain injury. Inj Prev. 2021. https://doi.org/10.1136/injuryprev-2019-043510.

Hedegaard H, Johnson RL, Garnett MF, Thomas KE. The 2020 International Classification of Diseases, 10th Revision, Clinical Modification injury diagnosis framework for categorizing injuries by body region and nature of injury. In: National Health Statistics Reports; no 150. Hyattsville: National Center for Health Statistics; 2020. https://www.cdc.gov/nchs/data/nhsr/nhsr150-508.pdf Accessed 31 Jan 2021.

Hedegaard H, Johnson RL, Warner M, et al. Proposed framework for presenting injury data using the International Classification of Diseases, Tenth Revision, Clinical Modification (ICD-10-CM). In: National Health Statistics Reports; no 89. Hyattsville: National Center for Health Statistics; 2016. https://www.cdc.gov/ nchs/data/nhsr/nhsr089.pdf Accessed 20 Dec 2020.

Hsia RY, Markowitz AJ, Lin F, et al. Ten-year trends in traumatic brain injury: a retrospective cohort study of California emergency department and hospital revisits and readmissions. BMJ Open. 2018;8:e022297. https://doi.org/10.1136/ bmjopen-2018-022297 epub 2018 Dec 14. https://www.ncbinlm.nih.gov/ pmc/articles/PMC6303631/ Accessed 18 Jan 2021.

Israeli Center for Trauma and Emergency Medicine Research, Gertner Institute, Sheba Medical Center. The Barell Injury Diagnosis Matrix, Classification by Body Region and Nature of the Injury. The Updated 2005. https://www.cdc. gov/nchs/data/ice/final_matrix_post_ice.pdf Accessed 12 Jan 2021.
Marr A, Coronado V, editors. Central nervous system injury surveillance data submission standards, 2002. Atlanta: US Department of Health and Human Services, CDC; 2004.

National Center for Health Statistics. Centers for Disease Control and Prevention. International Classification of Diseases, (ICD-10-CM/PCS) Transition Background, 2015. Available from: https://www.cdc.gov/nchs/icd/icd10cm_ pcs_background.htm Accessed on 1 Oct 2018.

National Conference of State Legislators. Traumatic Brain Injury Legislation. 2018. https://www.ncsl.org/research/health/traumatic-brain-injury-legislation.aspx Accessed 12 Jan 2021.

National Uniform Billing Committee. 2021. https://www.nubc.org/ Accessed on 1 Feb 2021.

Nikpay S, Freedman S, Levy H, et al. Effect of the Affordable Care Act Medicaid expansion on emergency department visits: Evidence from state-level emergency department databases. Ann Emerg Med. 2017;70(2):215-225.e6 https://pubmed.ncbi.nlm.nih.gov/28641909/ Accessed 18 Jan 2021.

Penfold RB, Zhang F. Use of interrupted time series analysis in evaluating health care quality improvements. Acad Pediatr. 2013;13(6):S38-44.

Peterson AB, Gabella B, Johnson J, Hume B, Liu A, Costich J, et al. Multi-site medical record review of emergency department visits for unspecified injury of head following the ICD-10-CM coding transition. ICD-10-CM injury epidemiology and surveillance methods supplement. Injury Prevention. 2021. https://doi.org/10.1136/injuryprev-2019-043517.

Sebastião YV, Metzger GA, Chisolm DJ, Xiang H, Cooper JN. Impact of ICD-9-CM to ICD-10-CM coding transition on trauma hospitalization trends among young adults in 12 states. Inj Epidemiol. 2021;8:4. https://doi.org/10.1186/s4 0621-021-00298-x.

Slavova S, Costich JF, Luu H, et al. Interrupted time series design to evaluate the effect of the ICD-9-CM to ICD-10-CM coding transition on injury hospitalization trends. Inj Epidemiol. 2018. https://doi.org/10.1186/s40621-01 8-0165-8.

Taylor CA, Bell JM, Breiding MJ, Xu L. Traumatic brain injury-related emergency department visits, hospitalizations, and deaths - United States, 2007 and 2013. MMWR Surveill Summ. 2017;66(9):1-16. https://doi.org/10.15585/mmwr. ss6609a1 https://www.ncbi.nlm.nih.gov/pmc/articles/PMC5829835/ Accessed on 31 Jan 2021.

Warwick J, Slavova S, Bush J, Costich J. Validation of ICD-10-CM surveillance codes for traumatic brain injury inpatient hospitalizations. Brain Inj. 2020;34: 13-4, 1763-1770. https://doi.org/10.1080/02699052.2020.1849801.

\section{Publisher's Note}

Springer Nature remains neutral with regard to jurisdictional claims in published maps and institutional affiliations.

Ready to submit your research? Choose BMC and benefit from:

- fast, convenient online submission

- thorough peer review by experienced researchers in your field

- rapid publication on acceptance

- support for research data, including large and complex data types

- gold Open Access which fosters wider collaboration and increased citations

- maximum visibility for your research: over $100 \mathrm{M}$ website views per year

At BMC, research is always in progress.

Learn more biomedcentral.com/submissions 